\section{Groups say med school training must evolve}

Medical training must adapt to include coursework covering evolutionary biology, according to a group of leading researchers.

Momentum for such change seems to be building. This past summer, the Association of American Medical Colleges (AAMC) and the Howard Hughes Medical Institute (HHMI) jointly issued a report on the topic, entitled Scientific Foundations for Future Physicians. It suggested that a key medical school competency should be to show an understanding of how evolution by natural selection leads to the diversity of life on earth.

Now a paper from attendees of a US National Academy of Sciences meeting on the subject is adding to the call (Proc. Natl. Acad. Sci. USA, doi:10.1073/pnas.0906224106; 2009). The paper, published last month, offers more detailed suggestions as to why and how the incorporation of evolution into medical education should occur.

"The case for ensuring that physicians and medical researchers are able to use evolutionary biology just as fully as other basic sciences is compelling," says Randolph Nesse, of the University of Michigan, lead author of the paper. "The constraints that inhibit change are severe, however. Most medical schools do not have a single evolutionary biologist on the faculty."
Nesse's paper cites examples of where evolutionary knowledge can benefit those working in medicine. An awareness of why humans have evolved the fever response, for example, could help doctors understand when it is safe to use drugs to block fever.

However, he says there are deeper reasons that medical students should learn more about evolutionary biology: "if many of our engineers believed in perpetual motion and thought that heavier objects fall faster, no one would say 'provide hard evidence that engineers who learn the laws of thermodynamics and gravity build better bridges," he points out. "We insist that engineers learn physics as a basic science. Physicians need to learn evolutionary biology for the same reason."

The joint AAMC-HHMI report from the summer emphasized a similar theme, although it did not go so far as to recommend specific curriculum changes.

"The AAMC does not collect specific data on medical school syllabi," says Ann Bonham, chief science officer of the Association of American Medical Colleges. "We expect that schools may include content related to evolutionary biology without labeling it as such.”

Daniel Cressey, London

\section{Industry tightens its purse strings}

Research funding from the US National Institutes of Health has increased dramatically since the 1990s, but money isn't flowing as freely from industry anymore, according to a new report. A survey of more than 2,000 randomly selected life science researchers across the US found that industry funding of studies fell by $8 \%$ from 1995 to 2006 . The authors note, though, that industry ties are still common: more than half of the life science faculty polled in 2007 had some connection with industry, such as serving as consultants (Health Aff. 28, 1814-1825; 2009).

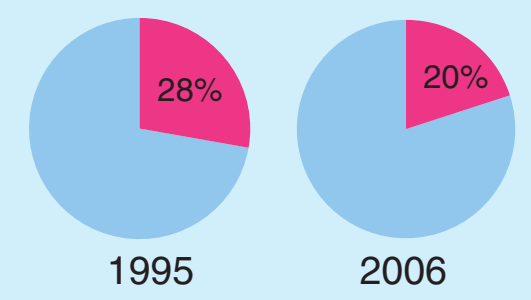

fraction of US university faculty members receiving industry funding for research

\title{
Willing subjects live longer but blur clinical trial results
}

Doctors have long known that a drug that works well in clinical trials will not always yield the same results in the broader population. Because women and the elderly are often underrepresented in trials, and some patients are deliberately excluded; for instance, controlled study results cannot necessarily be applied to all patients. A new study now strengthens the suggestion that a more insidious factor is also at play: researchers found that individuals with heart disease who refuse to enter into clinical trials die sooner than those who volunteer, even if the willing subjects are never actually recruited for experimental treatment (Eur. J. Heart Fail. 11, 1078-1083; 2009).

Andrew Clark, a cardiologist at Castle Hill Hospital in Cottingham, UK, and his colleagues asked over 2,300 people who came into a heart disease clinic to tick a box if they were prepared to volunteer for a clinical trial, and some were subsequently enrolled. Five years later, 35\% of those who had agreed had died, compared with around $55 \%$ of those who had refused.
By further comparing the prognosis of willing subjects who had not been recruited with that of volunteers who had eventually been enrolled, Clark found that participation alone did not predict survival. "It's not actually being in a trial that's beneficial, it's expressing willingness that is helpful," he says.

Why willing subjects live longer remains unclear. Volunteers could be more trusting, less stressed or less depressed, which could improve outcomes, speculates cardiologist Harlan Krumholz, of Yale School of Medicine in New Haven, Connecticut, who was not involved in the study.

More importantly, he says, the study shows another way in which the participants of clinical trials are not reflective of the broader patient population. Steven Joffe, an oncologist who studies clinical trial design at the Dana-Farber Cancer Institute in Boston, Massachusetts, adds that because self-selecting patients are creating the discrepancy-rather than doctors who are unwittingly or deliberately excluding

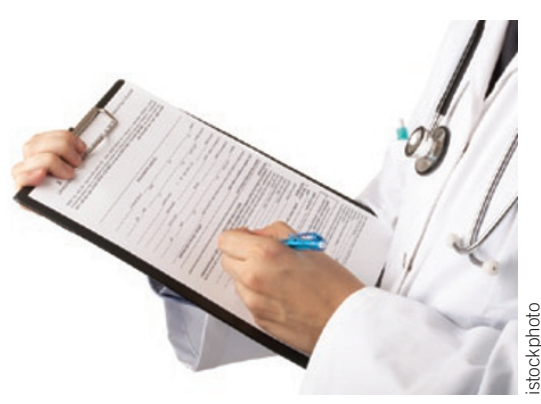

New spin: Volunteers skew results

patients - it could be difficult to avoid. Perhaps 'opt-out' recruitment strategies may result in more representative patient populations for some studies, he suggests.

Krumholz draws another conclusion. "This finding really emphasizes the importance of continuing to study the effects of drugs after their approval, when they're being used by millions of people."

Asher Mullard, London 